\title{
Study on Calculation Method of Contribution Rates of Water Pollution of Trans-Boundary Rivers
}

\author{
Xianzhong $\mathrm{ZENG}^{\mathrm{a}}$, Shouning $\mathrm{HAO}^{\mathrm{b} 1}$ \\ ${ }^{a}$ Administrative Office of Songbaishan Reservoir, Guiyang 550025, Guizhou, China \\ ${ }^{b}$ Xizang Agriculture and Animal Husbandry College, Linzhi 860000, Xizang, China
}

\begin{abstract}
The calculation of the contribution rates of the upstream and downstream administrative regions to water pollution of trans-boundary rivers is an important research subject. In this paper, a method based on the water quality mathematical model was proposed, which includes three steps: (1) Establishment of a model for a trans-boundary river; (2) Analysis of the pollution impact on the water quality at the control sections of the trans-boundary river; and (3) Calculation of the contribution rates to water pollution of the trans-boundary river. Taking Zhaosutai River, a transboundary river flowing through Jilin and Liaoning Provinces, as the study case, the contribution rates of these two provinces to water pollution of the river were determined by this method. The results showed that for the COD concentrations in the Control Sections of Laoqujiadian, Qijiazi and Dasijiazi of the main stream in January 2017 , the contribution rates of the upstream pollution loads we $96.2 \%, 81.0 \%$ and $70.5 \%$, respectively. The method of calculating the contribution rates to water pollution of trans-boundary rivers based on the mathematical water quality model proposed in this paper quantitatively can be used to identify the responsibilities of upstream and downstream administrative regions for water pollution of transboundary rivers.
\end{abstract}

Keywords: trans-boundary river; water pollution; liability identification; water quality model

\section{Introduction}

With the rapid development of society and economy, river environment is faced with increasing risks day by day $[1,2]$. Since a trans-boundary river may involve two or more administrative regions, the study on its water environment improvement is particularly complicated [3-7]. Due to the different functional orientation and management requirements of the administrative regions in the basin of a trans-boundary river, the conflicts between different parties on water resource protection and the of water environment improvement of the river are increasingly prominent [8-10]. Wherein, the responsibilities of upstream and downstream administrative regions for water pollution at the control sections of the trans-boundary river are often the focus of disputes [11]. When the water quality from upstream is too poor, it is often difficult to ensure that the water quality at the control sections of the downstream meets the standard, even if the 
pollution load into the river from the downstream administrative region is low. To quantitatively define the responsibilities of upstream and downstream administrative regions for water pollution at the control sections and thus develop a plan for water pollution prevention and control of upstream and downstream of the river is a key research topic to solve the water pollution disputes and improve the water environment of a trans-boundary river. Moreover, more and more attention has been paid to the joint prevention and control of trans-boundary rivers in recent years. The explorations of joint pollution prevention and control, law enforcement and ecological compensation across the upstream and downstream administrative regions have been carried out in many river basins $[10,12,13]$. The calculation of the contribution rates of the upstream and downstream administrative regions to water pollution at the control sections is an important basis for these explorations. Therefore, it is of great significance to study the calculation method of the contribution rates of upstream and downstream administrative regions to water pollution at the control sections.

In previous research, the calculation of the contribution rates of upstream and downstream administrative regions to water pollution at the control sections was mostly based on the negotiations between the two parties and no quantitative calculation method available. These methods are arbitrary and lack of scientificity, which can not correctly identify the responsibilities of the upstream and downstream administrative regions, and can not provide scientific and feasible support means for the water pollution control of cross-border rivers. In recent decades, as a research method that can quantitatively simulate and predict the evolution process of water environment, the mathematical model method is more and more used in the field of water environment management. It is an important research direction to analyze the water pollution liability of transboundary rivers by the mathematical model method. In this paper, a calculation method of the contribution rates to water pollution of trans-boundary rivers based on the mathematical water quality model was proposed and verified with Zhaosutai River, a transboundary river flowing through Jilin and Liaoning Provinces as the study case. The research results of this paper provide a quantitative research means for calculation of the contribution rates to water pollution of trans-boundary rivers and a scientific base for the development of ecological compensation agreements and water pollution control of trans-boundary rivers.

\section{Calculation Method of Contribution Rates}

For trans-boundary rivers, the pollutant concentration in water at the control sections of the downstream is affected not only by the pollutant input from the downstream, but also by the input from the upstream. In the calculation of the contribution rates to water pollution in trans-boundary rivers, it is difficult and important as well to quantitatively identify the impacts of the pollutant inputs from upstream and downstream regions on the water quality at the control sections. The simulation based on the mathematical water quality model is an effective solution to solve this problem. Accordingly, the calculation method of the contribution rates to water pollution in trans-boundary rivers will be proposed in the following discussion, of which the schematic diagram is shown in Figure 1 .

(1) Establishment of a hydrodynamic and water quality mathematical model for trans-boundary rivers. A hydrodynamic and water quality mathematical model for transboundary rivers is established by collecting the basic information of topography, 
hydrology and water quality of the trans-boundary river and completing the calibration and verification of the model.

(2) Analyses of the impacts of the pollutant inputs from upstream and local region on the water quality at the control sections. Provided that the measured water quality at the control sections satisfies the principle of linear superposition, the mathematical relationship of the measured water pollutant concentration at the control section, the water pollutant concentration created by the input from upstream and that from the local administrative region is as follows:

$$
C_{\text {mea }}=C_{\text {up }}+C_{\text {down }}
$$

Where $C_{\text {mea }}$ is the water pollutant concentration of a downstream control section, in $\mathrm{mg} / \mathrm{L} ; C_{\text {up }}$ is the water pollutant concentration measured at the upstream control section, in $\mathrm{mg} / \mathrm{L}$; and $C_{\text {down }}$ is the water pollutant concentration created by the input from the local administrative region, in $\mathrm{mg} / \mathrm{L}$.

$C_{\text {up }}$ is calculated by simulation of the established hydrodynamic and water quality mathematical model with the following relevant conditions: the water pollutant concentration measured at the upstream control section is used as the upstream pollutant concentration, and the pollutant input from downstream is assumed to be 0 . By subtracting $C_{\text {up }}$ from $C_{\text {mea, }}$, we can get $C_{\text {down }}$.

(3) Calculation of the contribution rates to water pollution of a trans-boundary river. For the water pollutant concentration at a downstream control section, the contribution rates of the upstream and downstream administrative regions are Rup and Rdown, respectively. The responsibilities of the upstream and downstream regions for the water pollution of the trans-boundary river can be quantitatively defined, according to the following equations:

$$
\begin{gathered}
R_{\text {up }}=C_{\text {up }} / C_{\text {mea }} \\
R_{\text {down }}=C_{\text {down }} / C_{\text {mea }}
\end{gathered}
$$

Where $R_{\text {up }}$ is the contribution rate of the upstream administrative region to the pollutant concentration at the control section, and $R_{\text {down }}$ is the contribution rate of the downstream administrative region.

\section{Case Analysis}

Taking Zhaosutai River, a trans-boundary river flowing through Jilin and Liaoning Provinces as the study case, this paper investigates the responsibilities of the two provinces for water pollution of this trans-boundary river by calculation of the contribution rates to the river water pollution with the hydrodynamic and mathematical water quality model mentioned above. The applicability of this model has been verified. 


\subsection{General Description of Zhaosutai River}

Zhaosutai River is the largest tributary of Liao River in Tieling region. It is adjacent to Dongliao River in the west, the watershed of Dongliao River in the north and east and Liangzi River in the south. The total length of main stream of Zhaosutai River is $213 \mathrm{~km}$ with a watershed area of $4583 \mathrm{~km}^{2}$. Zhaosutai River is in a mid-temperate zone with subhumid monsoon continental climate. It has an average annual rainfall of $601.2 \mathrm{~mm}$, an average annual precipitation of $600 \mathrm{~mm}$, and an average annual temperature of $7.3^{\circ} \mathrm{C}$.

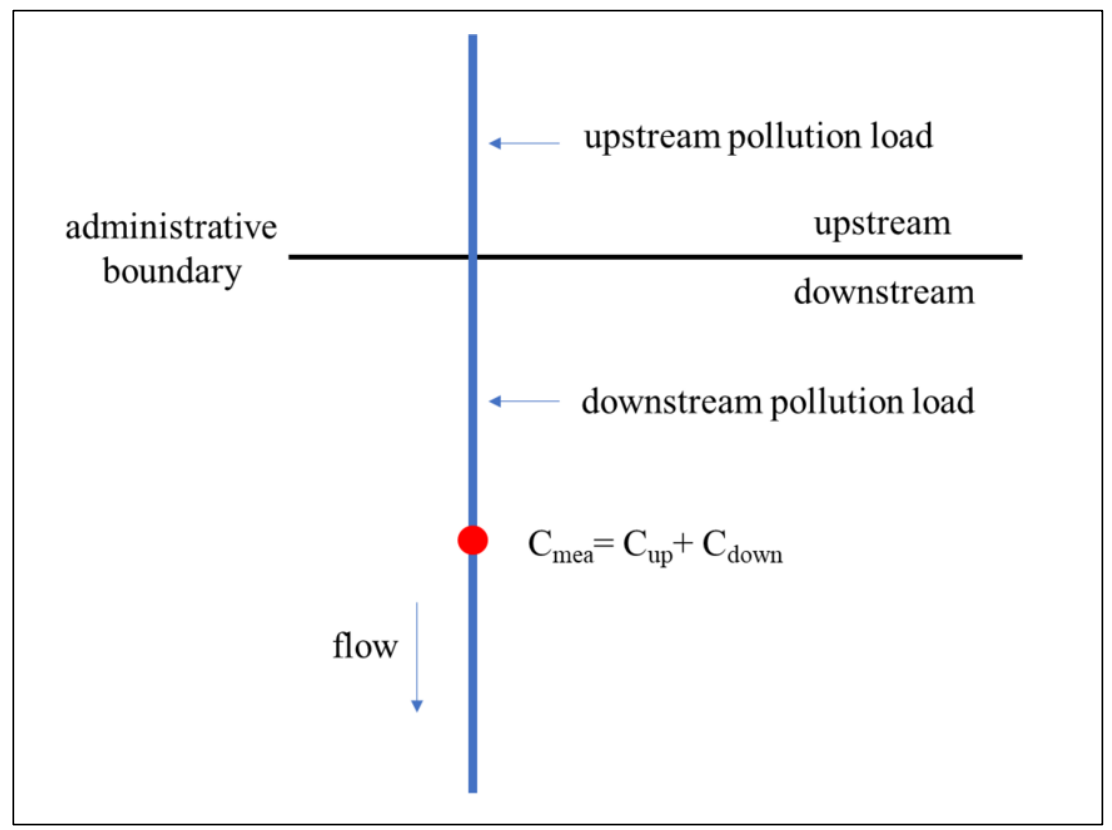

Figure 1. Schematic diagram of calculation method for the contribution rates to the water pollution of a trans-boundary river.

Zhaosutai River is a trans-boundary river flowing through Jilin and Liaoning Provinces. It originates from the south of Heli Peak in the west of Dahei Mountain in Lishu County, Jilin Province and flows through Siping City, Jilin Province. The main stream of Zhaosutai River and its tributary Tiaozi River flow through Changtu County, Tieling City, Liaoning Province and finally flows into Liao River in Tongjiangkou Town, Changtu County [14,15]. Zhaosutai River mainly flows through Changtu County of Liaoning Province. Its main stream in Changtu County is $157.82 \mathrm{~km}$ with a watershed area of $3004.1 \mathrm{~km}^{2}$. The schematic diagram of the water system of Zhaosutai River in Changtu County is shown in Figure 2.

There are five water functional zones along Zhaosutai River in Tieling City, including Jilin-Liaoning Riparian Buffer Zone, Heigang Agricultural Irrigation Zone, Huangjiuguan Agricultural Irrigation Zone, Tiaozi River Jilin-Liaoning Riparian Buffer Zone and Tiaozi River Linjia Agricultural irrigation Zone. The control sections in the water functional zones are S1 (Laoqujiadian), S2 (Qijiazi), S3 (Dasijiazi), S4 (Linjia), S5 (Chenjiatun), respectively. The spatial locations of the control sections are given in Figure 2 . 


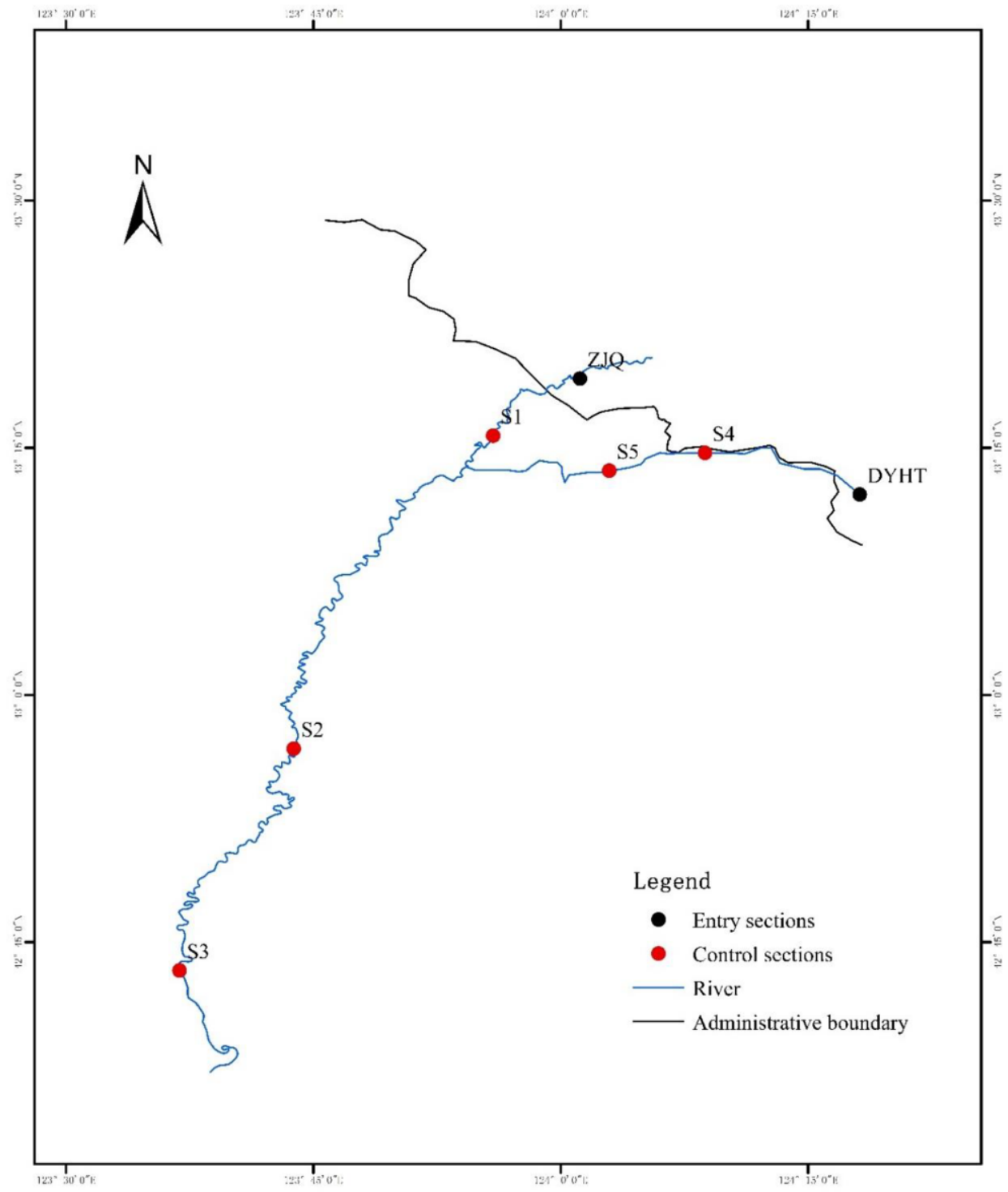

Figure 2. Schematic diagram of water system of Zhaosutai River in Changtu County. 


\subsection{Calculation of the Contribution Rates to Water Pollution of Zhaosutai River}

\subsubsection{Establishment of the Hydrodynamic and Water Quality Mathematical Model for Zhaosutai River}

In this paper, the hydrodynamic and water quality mathematical model for Zhaosutai River was established based on HEC-RAS model. HEC-RAS is a hydrodynamic and water quality simulation software developed by the Hydrological Engineering Center of the U.S. Army Corps of Engineers, which is mainly used for the calculation of onedimensional steady flow and unsteady flow in river courses and river networks. It has been widely used in the hydrodynamic and water quality simulation analysis of many rivers at home and abroad [16-20]. On the basis of HEC-RAS model, a hydrodynamic and water quality mathematical model of Zhaosutai River was established according to the water system situation and pollution sources of Zhaosutai River.

(1) Boundary Conditions and Initial Conditions. The upper boundary (i.e., the input point of upstream pollution load) conditions of the model were the daily flow rate and monthly water quality data of the provincial boundary control section, Zhangjiaqiao Section (ZJQ), where the main stream of Zhaosutai River enters Tieling City and those of the provincial boundary control section, Dongyihetun Section (DYHT), where Tiaozi River enters Tieling City. The lower boundary condition of the model was the daily water level of the control section of Zhaosutai River where the river enters Liaoning Province. The input points of downstream pollution loads were the 6 generalized confluence points of the tributaries of Zhaosutai River and the sewage outfalls into the river in Tieling region. The initial condition of the hydrodynamic model was zero in flow velocity, and the initial condition of the water quality model was the measured water pollutant concentration.

(2) Water Quality Indicators and the Model Step Size. $\mathrm{COD}$ and $\mathrm{NH}_{3}-\mathrm{N}$ were taken as the water quality indicators in the simulation of the mathematical model. According to the situation of data collection, January to December 2017 was chosen as the period for calibration and validation. Taking into consideration of both the calculation stability and efficiency, the calculation time step of the model was set to 5 minutes, and the length of the river course grid was set to $0.3-0.5 \mathrm{~km}$.

(3) Calibration and Validation of Model Parameters. The main parameters to be calibrated for hydrodynamic model and water quality mathematical model were river course roughness and the combined degradation coefficient of pollutants, respectively. In this paper, the roughness of natural river course was taken as the initial value of the roughness. By comparing the simulated and measured values of the water levels, the roughness of the main channel and the river beach are defined to be 0.027 and 0.018 , respectively. The combined degradation coefficient was calibrated by comparing the measured water quality data at the control sections with the simulated water quality data. The combined degradation coefficients of $\mathrm{COD}$ and $\mathrm{NH}_{3}-\mathrm{N}$ were defined to be $0.17 \mathrm{~d}^{-1}$ and $0.13 \mathrm{~d}^{-1}$, respectively.

The control sections at Laoqujiadian, Qijiazi, Dasijiazi, Linjia and Chenjiatun were chosen as water quality calibration and validation locations. The comparison of simulated and measured values of $\mathrm{COD}$ and $\mathrm{NH}_{3}-\mathrm{N}$ for each location during the model calibration and validation period is given in Figures 3 to 7 . It can be seen from the figures that the simulated values derived from the mathematical model agree well with the measured values of the water quality of Zhaosutai River. Therefore, the model can accurately simulate the distribution and transformation process of the pollutants in Zhaosutai River, and thus can be used to calculate the contribution rates from upstream and downstream to water pollution of Zhaosutai River. 

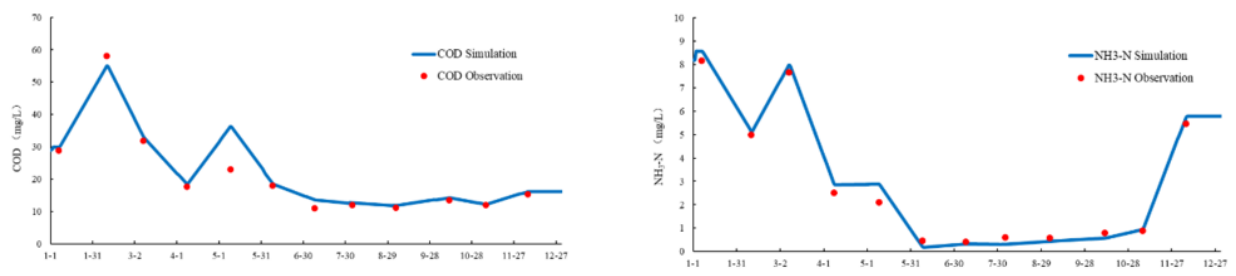

Figure 3. Comparison of simulated and measured values of $\mathrm{COD}$ and $\mathrm{NH}_{3}-\mathrm{N}$ at Laoqujiadian Control Section.
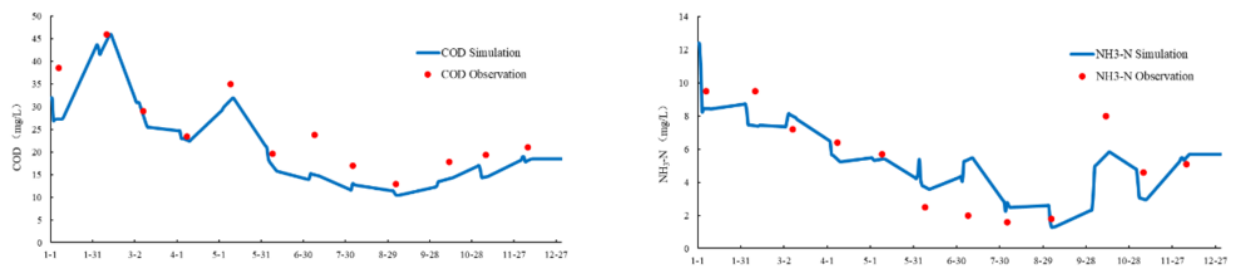

Figure 4. Comparison of simulated and measured values of $\mathrm{COD}$ and $\mathrm{NH}_{3}-\mathrm{N}$ at Qijiazi Control Section.
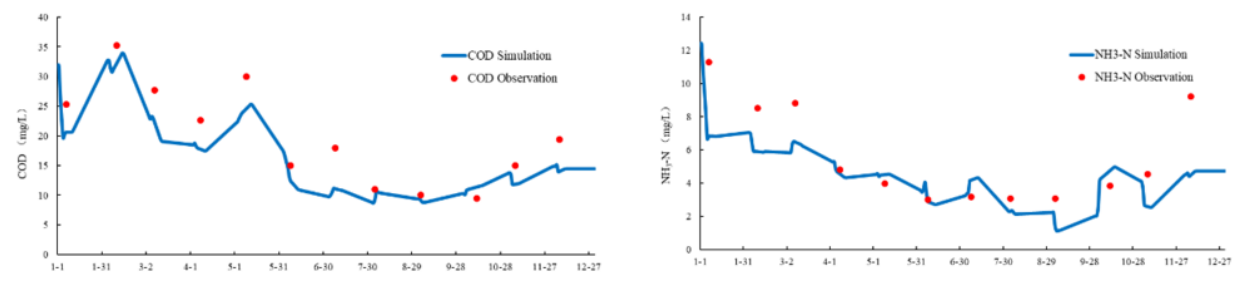

Figure 5. Comparison of simulated and measured values of $\mathrm{COD}$ and $\mathrm{NH}_{3}-\mathrm{N}$ at Dasijiazi Control Section.
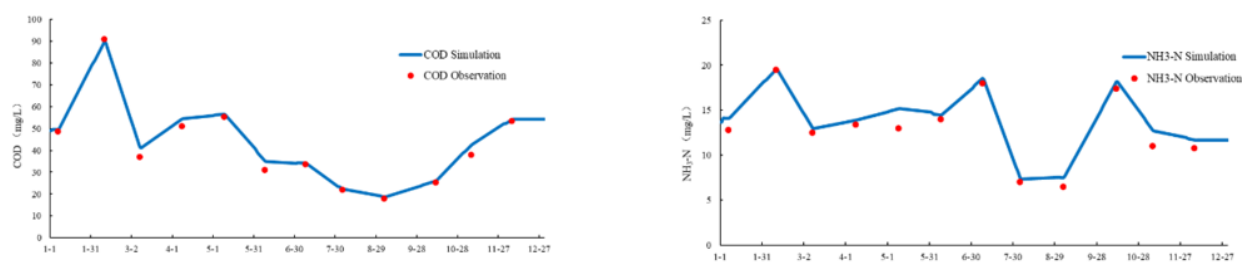

Figure 6. Comparison of simulated and measured values of $\mathrm{COD}$ and $\mathrm{NH}_{3}-\mathrm{N}$ at Linjia Control Section. 

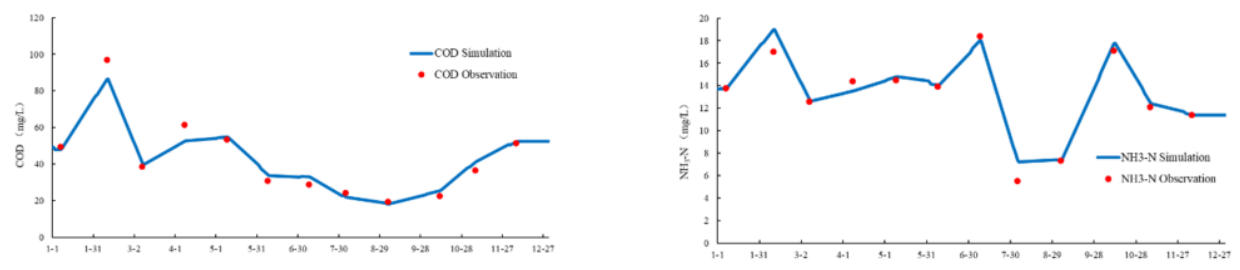

Figure 7. Comparison of simulated and measured values of $\mathrm{COD}$ and $\mathrm{NH}_{3}-\mathrm{N}$ at Chenjiatun Control Section.

\subsubsection{Analysis of the Pollution Impact on Water Quality at the Control Sections of Zhaosutai River}

The impact of the input of upstream and downstream pollution loads on the water pollutant concentrations of each of the control sections of Zhaosutai River in January of 2017 was analyzed through the established hydrodynamic and water quality mathematical model. The water pollutant concentration measured at the upstream control section in January of 2017 was taken as the input of upstream pollution load and assuming that the water pollutant concentration at the input point of downstream pollution load was 0 , then $C_{\text {mea }}$ was calculated by simulation under this condition. Provided that the water pollutant concentration at the input point of upstream pollution load was 0 , and the measured concentration at the downstream control section in January 2017 was used as the input of downstream pollution load, $C_{\text {down }}$ was calculated by simulation under this condition. The calculation results are given in Table 1 and Table 2.

It can be seen from Table 1 that for the main stream of Zhaosutai River, at Laoqujiadian Control Section in January of 2017 the COD concentration is $28.9 \mathrm{mg} / \mathrm{L}$, of which the COD concentration created by pollution load from upstream water is $27.8 \mathrm{mg} / \mathrm{L}$, and that created by the pollution load from downstream within Tieling region is only $1.1 \mathrm{mg} / \mathrm{L}$. It clearly shows that the pollution load from upstream water is the main factor affecting the water pollutant concentration at Laoqujiadian control section, while the downstream pollution load has little effect. The COD concentration at Qijiaz control section in January of 2017 is $38.6 \mathrm{mg} / \mathrm{L}$, of which the concentration from upstream water is $27.2 \mathrm{mg} / \mathrm{L}$, and the concentration from the downstream pollution load is $11.4 \mathrm{mg} / \mathrm{L}$, indicating that both upstream and downstream pollution loads have an important impact on the water quality at the control section, while the impact of upstream is greater than that of downstream. The COD concentration at Dasijiazi control section in January 2017 is $25.3 \mathrm{mg} / \mathrm{L}$, of which the concentrations from upstream and downstream pollution loads are $20.5 \mathrm{mg} / \mathrm{L}$ and $4.8 \mathrm{mg} / \mathrm{L}$, respectively. The law of the impact of the upstream and downstream pollution loads on the pollutant concentration of this control section is similar to that of Qijiazi Control Section. For Tiaozi River, the COD concentration at the control section of Linjia in January 2017 is $13.6 \mathrm{mg} / \mathrm{L}$, of which the pollutant concentrations from the upstream and downstream pollution loads are $12.6 \mathrm{mg} / \mathrm{L}$ and $1.0 \mathrm{mg} / \mathrm{L}$, respectively. The COD concentration at Chenjiatun Control Section is $13.8 \mathrm{mg} / \mathrm{L}$, of which the pollutant concentrations from the upstream and downstream pollution loads are $12.1 \mathrm{mg} / \mathrm{L}$ and $1.7 \mathrm{mg} / \mathrm{L}$, respectively. For the Control Sections of Linjia and Chenjiatun, the impact of the upstream pollution loads on the water quality in 
the control sections is significantly greater than that of the downstream pollution loads. The impact of upstream and downstream pollution loads on $\mathrm{NH}_{3}-\mathrm{N}$ concentration of Zhaosutai River is similar to that on COD concentration.

Table 1. Analysis of impact on COD concentrations at the five control sections of Zhaosutai River in January 2017.

\begin{tabular}{ccccc}
\hline River & Control Section & $\begin{array}{c}C_{\text {mea }} \\
(\mathrm{mg} / \mathrm{L})\end{array}$ & $\begin{array}{c}C_{\mathrm{up}} \\
(\mathrm{mg} / \mathrm{L})\end{array}$ & $\begin{array}{c}C_{\text {down }} \\
(\mathrm{mg} / \mathrm{L})\end{array}$ \\
\hline \multirow{2}{*}{ Main Stream of } & Laoqujiadian & 28.9 & 27.8 & 1.1 \\
Zhaosutai River & Qijiazi & 38.6 & 27.2 & 11.4 \\
& Dasijiazi & 25.3 & 20.5 & 4.8 \\
\multirow{2}{*}{ Tiaozi River } & Linjia & 48.7 & 46.5 & 2.2 \\
& Chenjiatun & 49.5 & 45.2 & 4.3 \\
\hline
\end{tabular}

Table 2. Analysis of impact on $\mathrm{NH}_{3}-\mathrm{N}$ concentration at the five control sections of Zhaosutai River in January 2017.

\begin{tabular}{ccccc}
\hline River & Control Section & $\begin{array}{c}C_{\text {mea }} \\
(\mathrm{mg} / \mathrm{L})\end{array}$ & $\begin{array}{c}C_{\mathrm{up}} \\
(\mathrm{mg} / \mathrm{L})\end{array}$ & $\begin{array}{c}C_{\text {down }} \\
(\mathrm{mg} / \mathrm{L})\end{array}$ \\
\hline \multirow{2}{*}{ Main Stream of } & Laoqujiadian & 8.2 & 8.0 & 0.2 \\
Zhaosutai River & Qijiazi & 13.5 & 8.5 & 5.0 \\
& Dasijiazi & 11.3 & 6.8 & 4.5 \\
\multirow{2}{*}{ Tiaozi River } & Linjia & 13.6 & 12.6 & 1.0 \\
& Chenjiatun & 13.8 & 12.1 & 1.7 \\
\hline
\end{tabular}

\subsubsection{Calculation of the Contribution Rates to Water Pollution of Zhaosutai River.}

Based on the analysis results of the impact on the water quality at each of the control sections of Zhaosutai River, the responsibilities of upstream and downstream pollution loads for water pollution of Zhaosutai River is clearly defined, as shown in Figure 8 and Figure 9. It can be seen from Figure 8 that for the COD concentrations in the Control Sections of Laoqujiadian, Qijiazi and Dasijiazi of the main stream of Zhaosutai River in January 2017 , the contribution rates of the upstream pollution loads are $96.2 \%, 81.0 \%$ and $70.5 \%$, respectively, while those of the downstream pollution loads are $3.8 \%, 19.0 \%$ and $29.5 \%$, respectively. For the COD concentrations in the control sections of Linjia and Chenjiatun of Tiaozi River, the contribution rates of the upstream pollution loads are $95.5 \%$ and $91.3 \%$, respectively, while those of the downstream pollution loads are $4.5 \%$ and $8.7 \%$, respectively. It can be seen from Figure 9 that for $\mathrm{NH}_{3}-\mathrm{N}$ concentrations at the Control Sections of Laoqujiadian, Qijiazi and Dasijiazi in the main stream of Zhaosutai River in January 2017, the contribution rates of the upstream pollution loads are $97.9 \%$, $62.7 \%$ and $60.5 \%$, respectively, while those of the downstream pollution loads are $2.1 \%$, $37.3 \%$ and $39.5 \%$, respectively. For the Control Sections of Linjia and Chenjiatun of Tiaozi River, the contribution rates of the upstream pollution loads are $92.6 \%$ and $87.7 \%$, respectively, while those of the downstream pollution loads are $7.4 \%$ and $12.3 \%$, respectively.

From the above analyses, it can be seen that the responsibilities of the upstream pollution loads for the pollutant concentrations in the control section are inversely 
proportional to the distance between the control section and the input points of the upstream pollution loads. The sequence of the responsibilities of the upstream pollution loads of Zhaosutai River for the pollutant concentrations in each of the control sections is as follows: Laoqujiadian > Qijiazi > Dasijiazi. Moreover, the responsibility of the upstream pollution load in each of the control sections of Zhaosutai River is greater than that of the downstream pollution load. This indicates that the key to water pollution control and water environment improvement of Zhaosutai River is to improve the upstream water quality.

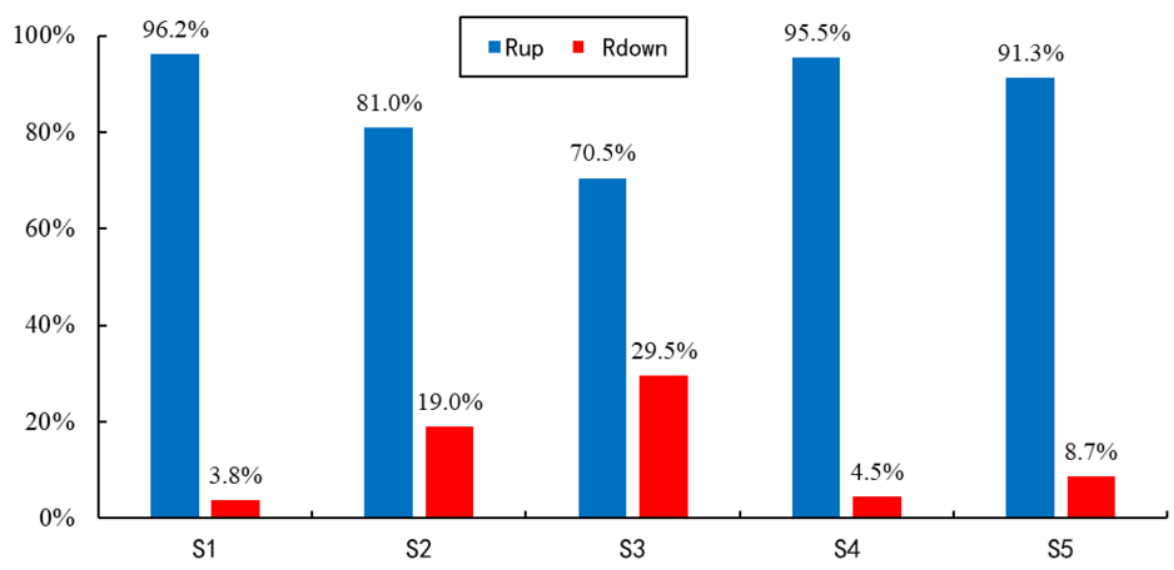

Figure 8. Calculation Results of the contribution rates of the upstream and downstream administrative regions of Zhaosutai River to COD concentrations in January 2017.

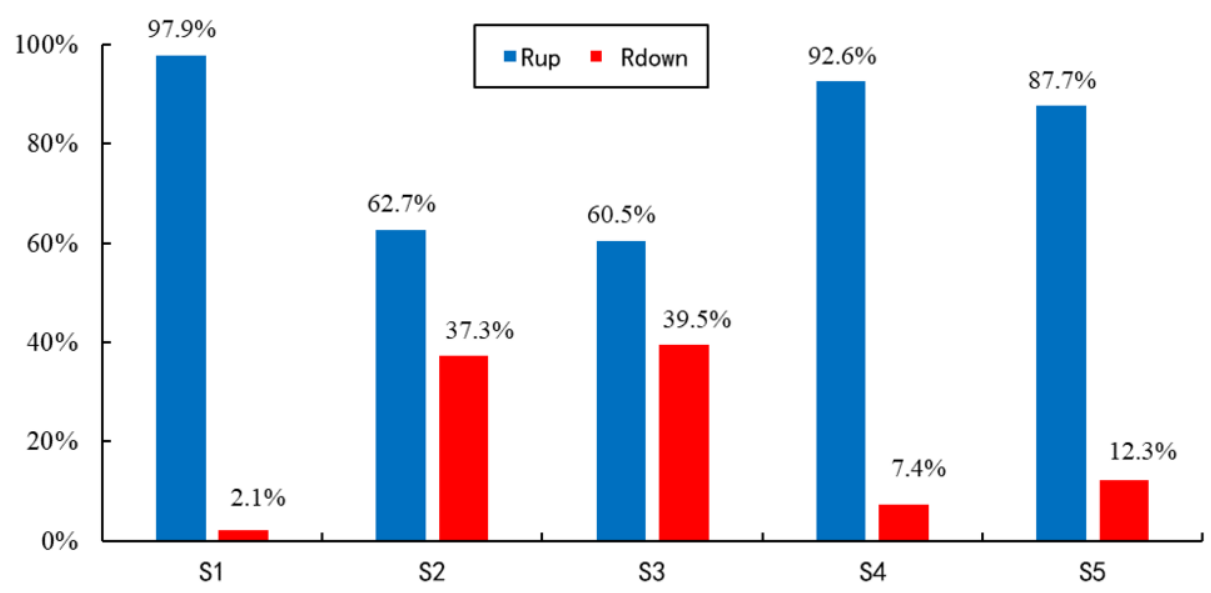

Figure 9. Calculation results of the contribution rates of the upstream and downstream administrative regions of Zhaosutai River to $\mathrm{NH}_{3}-\mathrm{N}$ concentrations in January 2017. 


\section{Conclusions}

In this paper, a method for calculation of contribution rates to water pollution of transboundary rivers was proposed based on the water quality mathematical model. The applicability of this method was validated with data from Zhaosutai River, a transboundary river. The main conclusions of the research are as follows:

(1) The method of calculation of the contribution rates of water pollution of transboundary rivers based on the water quality mathematical model mainly includes three steps: (a) establishing a mathematical model of water quality for the trans-boundary river; (b) analysing the pollution impact of the upstream and downstream pollution loads on the water quality in the control sections based on the water quality mathematical model; and (c) defining the responsibilities of the upstream and downstream pollution loads for the pollutant concentrations in the control sections according to the analysis results.

(2) The responsibilities of the upstream pollution load for the pollutant concentrations in the control section are inversely proportional to the distance between the control section and the input points of the upstream pollution loads.

(3) The responsibilities of the upstream pollution load in all control sections of Zhaosutai River are greater than those of the downstream pollution loads. This indicates that the key to water pollution control and water environment improvement of Zhaosutai River is to improve the upstream water quality and reduce the input of upstream pollution loads.

Though a quantitative calculation method of the contribution rates to water pollution of trans-boundary rivers was proposed, further research is needed on application of this method to water resources protection and water environment improvement, including development of ecological compensation agreements for trans-boundary rivers and the comprehensive control of water pollution of trans-boundary rivers.

\section{References}

[1] Xue XUE, Linong WANG, Haoran XING, Yu ZHAO and Zaizhao WANG. Characteristics of phytoplankton-zooplankton communities and the roles in the transmission of antibiotic resistance genes under the pressure of river contamination. Science of The Total Environment. 2021 Aug;780: 146452.

[2] Kang WANG, Pengxiang WANG, Renduo ZHANG and Zhongbing LIN. Determination of spatiotemporal characteristics of agricultural non-point source pollution of river basins using the dynamic time warping distance. Journal of Hydrology. 2020 Apr;583: 124303.

[3] Qiting ZUO, Bingbing WU, Wei ZHANG and Junxia MA. A theoretical method of water diversion for trans-boundary rivers and calculation of new scheme of water diversion for Yellow River. Resources Science. 2020 Jan; 42(01): 37-45.

[4] Lei YU, Libin LIU, Ruirui ZHU, Hailan LIN, Pei LIU, Rilong ZHU and Haiting PAN. Case Study on emergency monitoring of thallium pollution in trans-boundary rivers. Environment and Development. 2020 Sept;32(09): 138-9.

[5] Yang LI, Yuchi LUO, Jian XIAO and Yejia LV. Study on environmental protection countermeasures for drinking water sources of trans-boundary rivers in Guangdong Province. Environmental Science and Technology. 2019 Oct; 32(05):58-62.

[6] Ying TIAN, Beilei JIANG, Huojian HUANG and Fuxin SHEN. Study on risk factor identification and risk control of trans-boundary river safety. Water Resources and Hydropower Engineering. 2018 May;49(05): 9-15.

[7] Yong ZHONG, Hui LIU, Fuqiang TIAN, and Mu LIN. Prisoner's dilemma in trans-boundary river cooperation and the approach of cooperation evolution. Journal of Hydraulic Engineering. 2016 May; 47(05): 685-92.

[8] Jingjing DAI, Zhaoyi SHANG and Haoyang LI. Study on the ways of trans-boundary cooperation management for Taipu River. Water Resources Protection. 2016 Jan; 32(01): 142-7. 
[9] Fangzhou CHEN and Ruifang WANG. Study on long-term effect of ecological compensation mechanism for Xin'anjiang River Basin. Yangtze River. 2021 Feb;52(02): 44-9.

[10] Jin CHEN and Zhengjie YIN. Scientific subjects and countermeasures of ecological compensation for Yangtze River Basin. Journal of Yangtze River Scientific Research Institute. 2021 Feb;38(02): 1-6.

[11] Hong XING. Discussion on the settlement mechanism of trans-boundary water pollution disputes in Guangdong Province. Journal of Guangxi University for Nationalities (Philosophy and Social Sciences Edition). 2013 Jan;35(01): 176-80.

[12] Meichen PAN and Bo SONG. Willingness to accept compensation should be taken as the upper limit of ecological compensation standard. China Environmental Science. 2021 Feb;39(01):1-8.

[13] Tiangui LV, Fangping LIU, Li WANG and Anni KONG. Identification, causes, mechanism and countermeasures of water resources management conflicts in trans-boundary watersheds: a case study of Poyang Lake watershed. Yangtze River. 2021 Feb;52(02): 85-89.

[14] Xin RAN, Shijun SUN, Jiang FENG, Ming CUI, Zhenyu LONG and Sihan LIU. Study on performance optimization of water environment management based on control of total amount of pollutants: a case study of Zhaosutai River watershed in Jilin Province. South-to-North Water Transfers and Water Science and Technology. 2018 May;16(04): 128-135+145.

[15] Yong ZHANG, Jie TANG, Zhaoyang LI, Yuan BAI, Yu PAN and Xiaojiao WANG. Study on characteristics of agricultural non-point source pollution in Zhaosutai River watershed in Jilin Province Environmental Pollution \& Control. 2015 Dec;37(12): 29-34+40.

[16] Bo WU, Xuzhao WANG, Hongfei ZANG and Jianyun WANG. Determination of inundation range of mountain torrents in villages along Xiaodongchuan River watershed based on HEC-RAS and GIS. Water Resources and Power. 2016 Sept; 34(09): 52-5.

[17] Adeva-Bustos A, Hedger R D, Fjeldstad H P, Stickler M and Alfredsen K. Identification of salmon population bottlenecks from low flows in a hydro-regulated river. Environmental Modelling \& Software. 2019 Oct;120: 104494.

[18] Yongjia SONG and Daye WANG. Application and research of HEC-RAS model in water surface profile deduction for hills-and-plains compound river course in small watershed China Rural Water and Hydropower. $2020 \mathrm{Feb} ;(03): 146-9$.

[19] Xingnan ZHANG and Shunfeng PENG. Research and application of flood routing simulation system in plain areas. Journal of Hydraulic Engineering. 2010 July ;41(07) :803-9.

[20] Xiaogang LI, Cunchang HUANG and Yuzhu ZHANG. Study on flood hydrology of Wuding River at tenthousand-year scale based on HEC-RAS model Resources and Environment in the Yangtze Basin. 2020 May;29(02): 526-34. 